\title{
Gramsci, hegemonia, e as redes da sociedade civil global ${ }^{1}$
}

\author{
Hagai Katz - Ben Gurion University of the Negev ${ }^{2}$
}

\begin{abstract}
Resumo
Este estudo realiza o primeiro teste empírico, a um nível verdadeiramente global, de dois modelos contraditórios da sociedade civil global, que são propostos pelo pensamento neo-Gramnsciano, no sistema de governação global. O primeiro modelo pressupõe que a sociedade civil global é cooptada pela hegemonia capitalista e elites políticas, e promove interesses hegemónicos ao espalhar os valores neoliberais usando uma fachada de oposição. O segundo modelo perspectiva a sociedade civil global como a infra-estrutura através da qual a resistência contra- hegemónica, e em última análise um bloco histórico contra hegemónico, evoluirá para desafiar a hegemonia neoliberal. As previsões feitas por estas duas perspectivas, no que respeita a estrutura das redes da sociedade civil global, são testadas analisando uma matriz de relações entre 10,001 ONG's internacionais de uma amostra de ONGIs, retirada da base de dados da União das Associações Internacionais. Os resultados apoiam parcialmente as previsões e ambos os modelos, e levam à conclusão de que, presentemente, a sociedade civil global está numa fase de transição, mas que a infra-estrutura actual proporcionada pela rede de ONGIs global pode conduzir ao desenvolvimento futuro de um bloco histórico contra- hegemónico, isto se o enviesamento da rede na direcção do Norte for diminuindo. Serão apresentados os passos estratégicos necessários para que isto se torne uma realidade.
\end{abstract}

Palavras-chave : sociedade civil global, Gramsci, globalização, neoliberalismo, hegemonia

\section{Sociedade Civil Global: a atenuação da globalização neoliberal?}

A globalização e a sua ideologia dominante - neoliberalismo - tornou-se o guia hegemónico para a política económica e social global. O credo liberal é promovido activamente por um grupo de estados poderosos e organizações internacionais, e tornou-se hegemónico - "the only game in town" (Falk, 2000, p. 46). Poucos contestarão os resultados positivos da globalização neoliberal. Traz crescimento e avanço tecnológico, riqueza e conhecimento (Bigman, 2002). Torna os governos mais transparentes e consequentemente mais responsáveis perante uma audiência global , o que dificulta o encobrimento da prática de violação de direitos humanos (Kaldor, 2001). A globalização facilita a interacção humana dando mais opções para a troca de ideias graças à Internet e telecomunicações, bem como pelo aumento da mobilidade das pessoas, através do turismo e migração. Aquilo a que os críticos da globalização se referem é muitas vezes denominado pejorativamente como "globalização regressiva" (Kaldor et al., 2003) ou "globalização predadora" (Cox, 2002). Falk explica-o claramente:

\footnotetext{
${ }^{1}$ Uma versão em inglesa desta artigo foi publicada em Katz H., 2006. "Gramsci, Hegemony, and Global Civil Society Networks", Voluntas 14(7): 332-347. Traduçao: Marta Pedro Varanda.

2 Para correspondência: katzh@bqu.ac.il.
} 
O que é passível de objecção é condescender numa espécie de misticismo de mercado que concede hegemonia política à promoção do crescimento económico, desprezando os efeitos sociais adversos e moldando a política económica com base em certezas ideológicas que não atentam á realidade do sofrimento humano. (Falk, 2000, p. 48)

Os críticos argumentam que as políticas e práticas da globalização neoliberal aumentam a riqueza e o poder de poucos à custa de muitos. As instituições financeiras internacionais e as corporações transnacionais ganharam uma influência política substancial, o que Ihes permite influenciar as políticas a seu favor (Pollin, 2000) e minar a capacidade política dos pobres, enquanto aumentam o poder das novas redes de elites (Castells, 1989). O poder destas diminui a liberdade dos governos na condução das suas próprias políticas monetárias e fiscais, e as suas políticas deslegitimam o investimento expansivo no social (Esping-Andersen, 1996), causando empobrecimento massivo (Taylor et al., 2002).

A sociedade civil global é muitas vezes referida como a força que equilibra a globalização neo-liberal (Taylor, 2004). É apresentada como uma força reformista que desembocará num movimento global, corrigirá as desigualdades inerentes ao sistema de governação global, e atenuará e humanizará a globalização. Willets (citado em Dicken, 1998, p. 156) afirma que as ONG's são "a consciência do mundo". Florini and Simmons (2000) chamam-lhe "a terceira força " que actua como uma consciência global". Falk coloca a sociedade civil global, e especificamente as ONG's, no centro do que chama "Globalização a partir da base" (Falk, 2003, p. 285), o espaço onde crescem as ideologias alternativas.

No entanto esta pode ser uma visão excessivamente optimista. Na teoria da sociedade civil e hegemonia, a sociedade civil tem um papel mais complexo, sendo dialecticamente uma força reformadora e conservadora. Tem sido produzida pouca investigação que teste esta suposição optimista do papel da sociedade civil ao nível global. Este artigo pretende preencher este vazio, realizando uma análise empírica estrutural da rede global da sociedade civil, a primeira com esta escala. Através da análise das ligações inter-organizacionais entre milhares de ONG's internacionais (ONGI's), o artigo analisa a estrutura da rede global da sociedade civil, e se essa estrutura reflecte um papel hegemónico ou contra-hegemónico. Em conclusão sugiro alguns passos estratégicos que permitam aumentar o potencial contra-hegemónico da sociedade civil.

\section{Dialéctica Gramsciana e as redes globais da sociedade civil}

Que papel desempenha a sociedade civil global na perpetuação e transformação da hegemonia? A teoria da sociedade civil e contra-hegemonia de Antonio Gramsci fornece o enquadramento teórico para responder a esta questão. A noção de sociedade civil, retirada de referências contraditórias e ambíguas dos escritos de Gramsci numa prisão fascista, situa a sociedade civil entre o Estado com a sua legislação e capacidade, e a economia (Gramsci, 1971). Gramsci inclui na sociedade civil uma grande variedade de instituições não coercivas estruturas e actividades exteriores ao Estado e ao mercado como sindicatos, escolas, associações profissionais, educativas e culturais, partidos, e igrejas (Moen, 1998). É aqui que, em dialéctica, é mantida a ordem social hegemónica, mas é também o espaço da criatividade social, onde uma nova ordem social pode emergir.

\section{O modelo hegemónico de sociedade civil de Gramsci}

Em hegemonia, de acordo com o pensamento de Gramsci, um certo tipo de vida e pensamento é dominante, e é difundido por toda a sociedade para influenciar normas, valores e gostos, práticas políticas e relações sociais (Sassoon, 1982). 
Esta é baseada numa organização específica de consentimento, que tem uma base económica mas não está limitada a ela (Carroll, 1992). Isto porque resulta de uma combinação de coerção e consentimento, realizada através da cooptação hegemónica de grupos da sociedade civil, resultando numa "ortodoxia coerciva" (Persaud, 2001, p. 65).

Elementos da sociedade civil são cooptados pelo Estado, e usados para assegurar a condescendência das classes dominadas e assegurar a sua identificação com a ordem mundial hegemónica. Neste estado de coisas a sociedade civil torna-se uma parte de um Estado ampliado, e é utilizada pela classe dominante para formar e manter a sua hegemonia através de transformismo, ou cooptação. Neste processo a sociedade civil assimila ideias que vê como potencialmente perigosas, e deste modo cria consenso cultural e político (Cox, 1993). Torna-se um instrumento da revolução passiva, através da qual as forças hegemónicas permitem uma limitada (e até certo ponto, falsa) liberdade de auto-expressão para os grupos dominados, e com isso mantém a aceitação continuada das relações de forças presentes.

O projecto político do neo-liberalismo tem assistido à convergência dos estados e actores globais, incluindo as empresas transnacionais (TNCS) e as organizações governamentais internacionais (OGI's), em redor da doutrina neoliberal, e que resultou na instituição de uma nova ortodoxia (Tickell \& Peck, 2003). Este raciocínio relaciona-se directamente com a presente hegemonia do neoliberalismo, com o apoio dos Estados Unidos como estado dominante, bem como de um conjunto de outros actores estatais, inter-estatais e não estatais (tais como a União Europeia, Organização do Comércio Internacional, o Banco Mundial, e o Fundo Internacional Monetário) formando um bloco histórico, que inevitavelmente coopta as maiores organizações da sociedade civil, e usa-as para promover a sua agenda sob um disfarce de abertura.

Os que criticam a participação da sociedade civil global na governação global afirmam que existe uma concepção excessivamente optimista do papel que esta desempenha vis-à-vis as instituições hegemónicas. As ONGIs são pressionadas a imitar os estilos gestionários das empresas transnacionais e das IGOs de que dependem (Ramia, 2000). Os procedimentos e prestação de contas são distorcidos de acordo com as necessidades dos doadores e não com as dos parceiros ou beneficiários (Edwards, 1999). Para além disto, Edwards observa que muitas das parcerias entre as ONG's do Norte e do Sul são altamente desiguais e paternalistas. De acordo com Tvedt, o sistema de ajudas às ONGs é determinado pelos doadores e muitas das ONGs mais importantes são mais influenciadas pelas políticas estatais e dos doadores do que pela realidade local ou nacional (Tvedt, 2004). Assim os canais de ajuda são "a correia de trasnmisão do discurso dominante ligado a noções ocidentais de desenvolvimento" (Tvedt, 2004, p. 140). Esta argumentação é sustentada em várias análise de ONG's de desenvolvimento (Salm, 1999; Ulvila \& Hossain, 2002). As dependências de recursos definem a agenda das ONGIs de acordo com uma agenda dos doadores predominantemente liberal, politica e economicamente. (Fowler, 1996).

Algumas ONGIs desempenham um papel mais activo no bloco histórico hegemónico presente. Com base na análise de 5 grupos de políticas, Carroll and Carson consideram os núcleos políticos como fóruns para a construção da hegemonia neoliberal transnacional. Estas ONGIs, incluindo a Câmara Internacional do Comércio sediada em Paris , o Conselho Mundial de Negócios para o Desenvolvimento Sustentável [World Business Council for Sustainable Development], e outros, estão profundamente inseridos, numa rede global de líderes empresariais (Carroll \& Carson, 2003). 


\section{O modelo de sociedade civil contra-hegemónico de Gramsci's}

Mas a sociedade civil à la Gramsci é também de onde emerge a liderança e os movimentos da base, quando a privação se mobiliza através da consciencialização, e a revolução pode ser preparada. A hegemonia necessita da contra-hegemonia - a hegemonia e a contra-hegemonia devem ser vistas como "movimentos duplos simultâneos" formados em reciprocidade - a hegemonia dá forma à contra-hegemonia, e os esforços contra-hegemónicos levam as forças hegemónicas a realinharem-se e a reorganizarem-se (Persaud, 2001, p. 49). A sociedade civil, e não o Estado como em Hegel, é o momento activo e positivo do desenvolvimento histórico. É o espaço criativo, de onde grupos subalternos, motivados por intelectuais, se podem unir, formar um bloco histórico, e travar uma guerra de posição contra hegemónica para alterar a sociedade (Sassoon, 1982).

A hegemonia ao nível global é produzida por um modo dominante de produção que é exportado por estados dominantes e instituições, e que penetra outros estados e instituições; logo, a contra-hegemonia tem que ser constituída por relações sociais internacionais complexas, através das quais as classes sociais nos diferentes países se conectam, formando um bloco histórico contra-hegemónico global. AS ONGIs são a avant-garde neste lento processo de consciencialização, organização e protesto (Cox, 1993). Adaptando o pensamento de Gramsci à nossa época, Cox argumenta que a contra - hegemonia ao domínio do capital global só pode ser desenvolvida a partir dos auspícios de uma sociedade civil global (Cox, 1993; 1996; 2002).

Como se consegue mudar? O conceito de hegemonia de Gramsci diz respeito à qualidade em que as classes dominantes utilizam o Estado para coagir e ao mesmo tempo obter consentimento da sua dominação junto da sociedade civil. Dado que isto marginaliza os interesses de alguns dos grupos subordinados, estes organizam-se no único espaço que lhes está disponível - a sociedade civil. Para Gramsci, as mudanças socio-económicas meramente estabelecem as condições nas quais a transformação se torna possível. O que é crucial para que a mudança seja possível, são os ajustamentos nas "relações e força" a nível politico, que são afectados pelo grau de organização política e de agressividade das forças rivais, a força das relações que conseguem mobilizar, e o seu nível de consciência política (Forgacs, 1988).

Várias condições têm que surgir para que a mudança hegemónica aconteça. Estas podem ser sumarizadas em, organização, ideologia, e acção. No contexto do movimento global contra-hegemónico para atenuar a globalização neo-liberal, a primeira condição envolve a criação de um "bloco histórico" contra-hegemónico uma coligação de grupos, que fazem a ponte entre a miríade de grupos desfavorecidos como consequência da globalização. A segunda condição relaciona-se com a adopção de uma ideologia social-democrata pelas ONGIs, o que se opõe à agenda neo-liberal da hegemonia existente. Finalmente, a formação de um bloco-histórico contra hegemónico que conduzirá a uma "guerra de posições" - uma luta integrada intelectual e política, numa variedade de níveis da ordem mundial emergente - de local para global - que lentamente vai construindo as fundações de um novo regime (Rupert, 1993).

O conceito de bloco histórico é central para o conceito de mudança social no pensamento Gramsciano. Para que o "elemento subalterno não seja uma coisa [objecto ou idealização] mas uma pessoa histórica" ele tem que ser "um agente , necessariamente activo e que toma iniciativa " (Gramsci, 1971, pp. 144, 332337). AS alianças desenvolvidas na mobilização contra-hegemonica tem que ir para além das classes, e incluir várias forças sociais - uma aliança das classes com grupos sociais-democratas. Esta aliança prefigura uma nova ordem, uma convergência do trabalho com os novos movimentos sociais, através de diferentes 
formas de ligação ou "construção de pontes" (Carroll, 1992, p. 12). Nesta linha, Bocock (1986) defende um envolvimento hegemónico, novo, radical e moral, de todos os maiores grupos radicais. Bocock lista o trabalho, os movimentos de mulheres, os movimentos para a paz, os grupos religiosos, os ambientalistas, as organizações étnicas, ente outros. Esta é uma concepção radical-pluralista que localiza o desenvolvimento da contra-hegemonia na "multiplicidade de antagonismos", desenvolvendo-se nas, e através das, relações sociais da sociedade civil (Ratner, 1992, p. 235). Para que o bloco histórico seja eficaz tem que ser uma coligação de forças, que não duplique as disparidades inerentes ao sistema-mundo actual, que evite localismo ou nacionalismo, que promova a solidariedade global através de redes que liguem o local ao global (Amoore et al., 2000; Gills, 2000) - uma estratégia de resistência unificadora, não homogeneizadora.

Vários estudos, embora raramente apliquem os conceitos Gramscianos, descrevem o movimento contra-hegemónico. De forma notável, Keck and Sikkink (1998) demonstram que a influência política típica da diplomacia das ONG, utiliza as ligações em rede para influenciar os actores mais poderosos, usando-os para promover os objectivos da rede. As ONGs do Sul utilizam as ONGs do Norte para pressionar indirectamente as políticas na sua região. Para tornar isto possível, as redes incorporam as organizações do Norte e do sul, e entre estas ultimas inccroporam especialmente aquelas capazes de chegar às IGOs e que têm importância suficiente nos seus próprios países. Também Diani (2003) nota que a diversidade da rede é multiplicadora, pois abre canais de comunicação para varias populações de organizações, e que a diversidade de temas está também ligada com diversidade estratégica, flexibilidade e ajustamento á mudança.

A importância da diversidade das redes para o sucesso das iniciativas progressivas das ONGs é demonstrado por Khagram (2002), que argumenta, a propósito das barragens do vale de Narmada na Índia, que as coligações de sucesso mostram a eficácia da aliança local-global e povo-elite; bem como da mistura de organizações com diferentes ideologias e estratégias de acção. De forma semelhante, Castells, na sua análise dos Zapatistas, mostra como as identidades de resistência convergem para formar identidades de projecto, direccionadas para a transformação da sociedade de acordo com os valores de resistência aos interesses dominantes estabelecidos pelos fluxos globais de capital e poder. Isto é possível expandindo as campanhas em redes globais, e a partir daí elevá-las da operação em espaços de acção para a operação através de fluxos, tornando-as visíveis onde realmente é importante (Castells, 1997).

\section{A questão da investigação}

A teoria Gramsciana oferece portanto dois modelos de governação global que se opõem, e que têm uma ligação directa com a hipotética estrutura da sociedade civil global. Até ao momento a literatura tem demonstrado suporte empírico para ambos os modelos, mas nenhum destes modelos foi ainda testado ao nível global, nem para além da análise de temas específicos. De forma a avaliar nas estruturas actuais da sociedade civil, qual destes dois modelos é suportado, há que analisar as redes da sociedade civil global e testá-las à luz desses modelos. Assim a pergunta de investigação é a seguinte : Qual das previsões dos dois modelos concorrentes da teoria de Gramsci está de acordo com a estrutura actual da sociedade civil? Mais especificamente :Será que estrutura actual da sociedade civil global apoia predominantemente a noção de uma sociedade civil global como parte da hegemonia liberal global, ou um bloco histórico contra-hegemónico, que se opõe à hegemonia global neo-liberal? 
Se a sociedade civil global é uma parte da hegemonia neoliberal, deveria reflectir as desigualdades presentes da ordem mundial. Logo, esperar-se -ia que sob tais condições, a estrutura da sociedade civil fosse desigual, com grandes disparidades norte-sul em termos do número de ONGIs pertencentes à rede e na distribuição das suas ligações, e também com uma estrutura centro-periferia fortemente polarizada, na qual o centro é constituído predominantemente por ONGIs dos países desenvolvidos.

Numa situação de hegemonia, espera-se que as forças hegemónicas sejam capazes de prevenir a formação de um bloco histórico, e nesse caso depararíamos com uma rede da sociedade civil global substancialmente fragmentadas, consistindo em muitas sub-redes regionais fracamente conectadas entre si e específicas a certos temas. Da mesma forma, como os actores hegemónicos se empenham activa e estrategicamente na sociedade civil, de forma a promover os valores e as práticas hegemónicas, esperar-se-ia que as organizações intergovernamentais (IGOs) se unissem com as ONGIs mais centrais. O resultado seria uma distribuição desigual das ligações das ONGIs com as IGOs, em que as ONGIs dos países desenvolvidos têm consideravelmente mais laços com as IGOs do que as suas equivalentes dos países em desenvolvimento. Para além disto, deveríamos esperar que as organizações que têm um número relativamente mais alto de ligações com IGOs fossem as que desempenham um papel mais central na rede, isto é, as que estão melhor conectadas .

Se na verdade a sociedade civil global tem vindo a desenvolver um bloco histórico contra-hegemónico, deveria, de acordo com Gramsci, formar uma coligação de todos os grupos subalternos numa sociedade. Todos eles deviam interagir entre si, o que em análise de redes quer dizer que muitas das ligações possíveis existem na realidade, e que a densidade da rede será alta. Um bloco histórico contra hegemónico também é caracterizado por uma estrutura igualitária, na qual o poder está descentralizado, e está distribuído de forma mais ou menos justa e semelhante, entre todos os grupos presentes no bloco histórico (Batliwala, 2002). Além disso, o contra movimento deve envolver organizações interessadas em temas diversos, representando interesses diferentes, grupos, e regiões - deve ser diversificado e inclusivo .

Um bloco histórico é bem integrado por definição, dado que é uma amálgama de todos os grupos subalternos num único contra-movimento hegemónico. Uma rede segmentada consistindo em sub-redes exclusivas - regionais, temáticas ou baseadas em classes - será um obstáculo à formação de um bloco histórico contra-hegemónico.

\section{Dados e Métodos}

Para estimar a estrutura da rede da sociedade civil global, este artigo analisa as ligações inter-organizacionais entre as ONGIs. Certamente que as ONGIs não são os únicos actores na sociedade civil global, e o enfoque nas organizações deixa de fora aspectos importantes das ligações transnacionais inter-pessoais. No entanto, as ONGIs são os actores da sociedade civil global mais visíveis e tangíveis, e são o elemento central da sua infra-estrutura (Anheier \& Katz, 2003; Boli \& Thomas, 1997; Castells, 1997; Cox, 1993; Falk, 2003). Além do mais, as ligações entre as organizações formais, são, por definição, tendencialmente menos efémeras que as ligações individuais, e assim o estudo de tais ligações deixa-nos entrever aspectos das estruturas de longo-prazo da sociedade civil global, as de maior importância para o desenvolvimento de um movimento global viável. Nenhuma visão da sociedade civil global pode estar completa sem as ligações interorganizacionais ao nível individual, e sem as ligações inter-pessoais. Mas os dados sobre tais ligações são raros e o custo de os obter proibitivo. 
Mesmo para as ONGIs os dados existentes estão longe de serem os ideais. Para obter repostas preliminares à questão de investigação, são necessários dados de uma parte substancial das milhares de ONGIs que operam nas diferentes áreas e zonas do mundo. Felizmente, a Union of International Associations (UIA) acedeu a partilhar informação de um subconjunto de ONGIs cujos dados recolhem. As organizações consideradas relevantes para o estudo foram seleccionadas de acordo com o seu objecto declarado. O critério utilizado, para definir a sua relevância, foi baseado nos temas dos painéis do comité organizador central do Fórum Social Mundial de 2004. O Fórum Social Mundial é considerado ser o evento principal e mais compreensivo da sociedade civil global dos últimos anos. È o evento mais global, em termos da participação e da abordagem. Também serve de ponto de encontro para as redes existentes, e de rampa de lançamento para novas redes (Cock, 2004). Em consequência, assume-se que este estudo reflecte as questões centrais relacionadas com os actores da sociedade civil global do presente. Os painéis cobriam a seguinte lista de temas: Globalização, governação global, e o estado-nação; Organização do Comércio Mundial; Militarismo, guerra e paz; partidos políticos e movimentos sociais ; Media, cultura, e conhecimento; guerras contra as mulheres, mulheres contra as guerras; globalização económica e segurança social; a globalização e as suas alternativas; Descriminação e opressão: Racismo e regime de castas ; trabalho e o mundo do trabalho; a luta contra o neoliberalismo e a guerra, e o papel do Fórum Social Mundial; exclusão e opressão religiosa, étnica e linguística; alimentação e recursos naturais (WSF, 2004). Os grupos de temas da UIA compatíveis com estes eram seleccionados, e as organizações que deles faziam parte eram acrescentadas à nossa base de dados (para uma discussão mais pormenorizada da metodologia ver Katz \& Anheier, 2005). Ao todo 181 grupos temáticos correspondiam os temas destes painéis.

Todas as organizações nestes grupos temáticos, bem como as organizações com quem estas têm ligações, foram incluídas nas bases de dados, resultando numa matriz quadrada de 10,001 organizações (48.5\% do número total de ONGIs da base de dados da UIA ), com mais de 100 milhões de ligações possíveis entre elas. As ligações entre as organizações desta matriz eram determinadas com base nas ligações referidas na base de dados da UIA, incluindo ligações relacionadas com a fundação ou o estabelecimento, ligações estruturais tais como as que existem entre organizações irmãs ou subsidiárias, ligações através de partilha ou transferência mútua de funcionários chave, ligações financeiras, ligações através de actividades conjuntas, ligações via publicação conjunta ou publicações acerca de outra organização, e ligações entre as organizações e os seus membros. Os dados recebidos da UIA não incluíam a distinção entre estes tipos de ligações. Assim, uma ligação entre duas organizações da matriz quereria dizer que existia uma ligação de qualquer um dos tipos mencionados. Dados adicionais das organizações desta matriz incluíam informação sobre as classificações dos temas, o número de ligações que cada organização da matriz tem com organizações intergovernamentais, e país da sede. Para além da base de dados principal, foram usadas duas outras bases de dados já disponíveis, de forma a obter resultados comparativos com outros padrões globais: fluxos comerciais e ligações ente embaixadas e consulados .

\section{Análise}

$\mathrm{Na}$ análise desta base de dados foram usados uma variedade de métodos da análise de redes, e, fundamentalmente, o programa UCINet 6 (Borgatti et al., 2002). Grande parte da análise teve como base a rede constituída por $10,001 * 10,001$ ONGIs. 
A análise de inclusão exigia o cálculo da distribuição dos nodos e ligações através dos níveis de rendimento das regiões e dos países. Para isso foi calculado, usando o ESRI's ArcGIS 9.0 (ESRI, 2005), um mapa simples da densidade das ligações. Para a análise da integração da rede forma realizadas 3 análises diferentes mas complementares : a análise dos componentes para determinar se a rede das ONGIs era uma só ou se estava dividida em sub-redes ; a análise de correspondência para determinar se a rede, ou as suas diversas sub-redes, consistiam em clusters relativamente densos que estão inter-ligados de forma folgada; finalmente, calcularam-se os, índices E-I para determinar se a rede é caracterizada por ligações inter-grupo ou intra grupo. O índice E-I envolve a comparação das ligações que envolvem actores de tipos diferentes com as que envolvem actores do mesmo tipo . O índice varia entre +1 e -1 , sendo um resultado positivo revelador de ligações maioritariamente inter-grupo [McGrath \& Krackhardt, 2003].)

Dado que não existem outras bases de dados de redes globais comparáveis à obtida com as ONGIs, pensou-se ser adequado construir redes globais que permitissem a comparação entre a rede das ONGIs e outras redes. Assim, condensou-se a rede de ONGIs numa matriz de países por ONGIs, e obtiveram-se dados relativos ás ligações entre embaixadas e consulados, e também do comércio externo (usámos os dados de Maher, 2001 e da UN Commodity Trade Statistics Database, http://unstats.un.org/unsd/comtrade). A partir destes dados construíram-se três matrizes das redes entre países ( relações entre países através das ONGIs, através da interacção entre embaixadas e consulados, e trocas comerciais), que incluem 237 países. Estas matrizes foram usadas para comparar a densidade da rede de ONGIs com a das redes hegemónicas dos estados e do capitalismo global, e para comparar as semelhanças entre estas 3 redes. A semelhança entre as redes foi testada através do calculo da dimensão central [coreness] - assumindo que a rede tem uma estrutura de centroperiferia, calcula a distância de cada organização relativamente ao centro. Realizámosa análise de clusters das medidas de distância de forma a detectar se existe uma estrutura de centro-periferia nas três redes de países (Borgatti \& Everett, 1999).

Dado que os testes estatísticos tradicionais assumem que as observações são independentes, não sãoaplicáveis ao dados relacionais, pois aqui os valores de cada observação são definidos pela sua relação com outras observações. Logo, usam-se métodos alternativos, predominantemente bootstrapping de iterações aleatórias da base de dados analisada (Snijders \& Borgatti, 1999).

\section{Resultados}

\section{Cobertura global e inclusão}

Para iniciar, a rede da sociedade civil global é dominada por economias cujos rendimentos são altos. A distribuição das organizações e ligações na rede global de ONGIs está enviesada na direcção das nações mais ricas, ou mais desenvolvidas (ver Quadro 1). 


\begin{tabular}{|c|c|c|c|c|}
\hline & ONGIS & $\%$ & Ligações* & $\%$ \\
\hline \multicolumn{5}{|l|}{ Região } \\
\hline $\begin{array}{l}\text { Ásia de Leste e } \\
\text { Pacífico }\end{array}$ & 803 & $8.0 \%$ & 4,653 & $7.8 \%$ \\
\hline Europa \& Ásia Central & 248 & $2.5 \%$ & 1,430 & $2.4 \%$ \\
\hline $\begin{array}{l}\text { América Latina \& } \\
\text { Caraíbas }\end{array}$ & 504 & $5.0 \%$ & 3,083 & $5.2 \%$ \\
\hline $\begin{array}{l}\text { Médio Oriente \& Norte } \\
\text { de África }\end{array}$ & 187 & $1.9 \%$ & 1,205 & $2.0 \%$ \\
\hline América do Norte & 2,260 & $22.6 \%$ & 12,623 & $21.1 \%$ \\
\hline Sul da Ásia & 185 & $1.8 \%$ & 1,206 & $2.0 \%$ \\
\hline África Sub Sahariana & 454 & $4.5 \%$ & 2,753 & $4.6 \%$ \\
\hline Europa Ocidental & 5,097 & $51.0 \%$ & 31,285 & $52.4 \%$ \\
\hline \multicolumn{5}{|l|}{ Nível de Rendimentol } \\
\hline Baixo Rendimento & 587 & $5.9 \%$ & 3,619 & $6.1 \%$ \\
\hline Rendimento Médio & 1,107 & $11.1 \%$ & 6,628 & $11.1 \%$ \\
\hline Alto Rendimento & 8,044 & $80.4 \%$ & 47,991 & $80.4 \%$ \\
\hline
\end{tabular}

Quadro 1. Nodos e ligações por região e nível de rendimento

* Cada ligação é contada duas vezes: uma vez quando é enviada (out-degree) e outra vez quando é recebida (in-degree)

A distribuição dos nodos e ligações por países é ainda mais concentrada; mais de metade dos nodos e ligações na rede de ONGIs está localizada em 5 países: EUA, Reino Unido, Bélgica, França, e Alemanha . Ao todo, entre os 21 países que estão no topo da rede em termos do número de nodos e ligações, só quatro são de países não ocidentais (Japão, Índia, Quénia e as Filipinas), dos quais só os últimos três são países em desenvolvimento. A Figura 1 acrescenta o ângulo espacial a esta clara prevalência ocidental e nórdica. O mapa da densidade de ligações de ONGIs revela um padrão claro - concentração extrema de ligações na Europa Ocidental e a costa do Nordeste da América do Norte, acrescido de um foco mais pequeno no Japão e Austrália. Até agora, podem-se notar alguns focos emergentes no sul global, Índia, Quénia, África do Sul, Argentina, Nigéria, e Brasil. Ao invés, vastas áreas no mundo parecem estar completamente fora do alcance da rede global de ONGIs (é importante notar que isto se refere só à localização formal da sede das ONGIs, e é possível que as ONGIs operem em outras áreas ou tenham ligações ao nível local com organizações de outras áreas). 


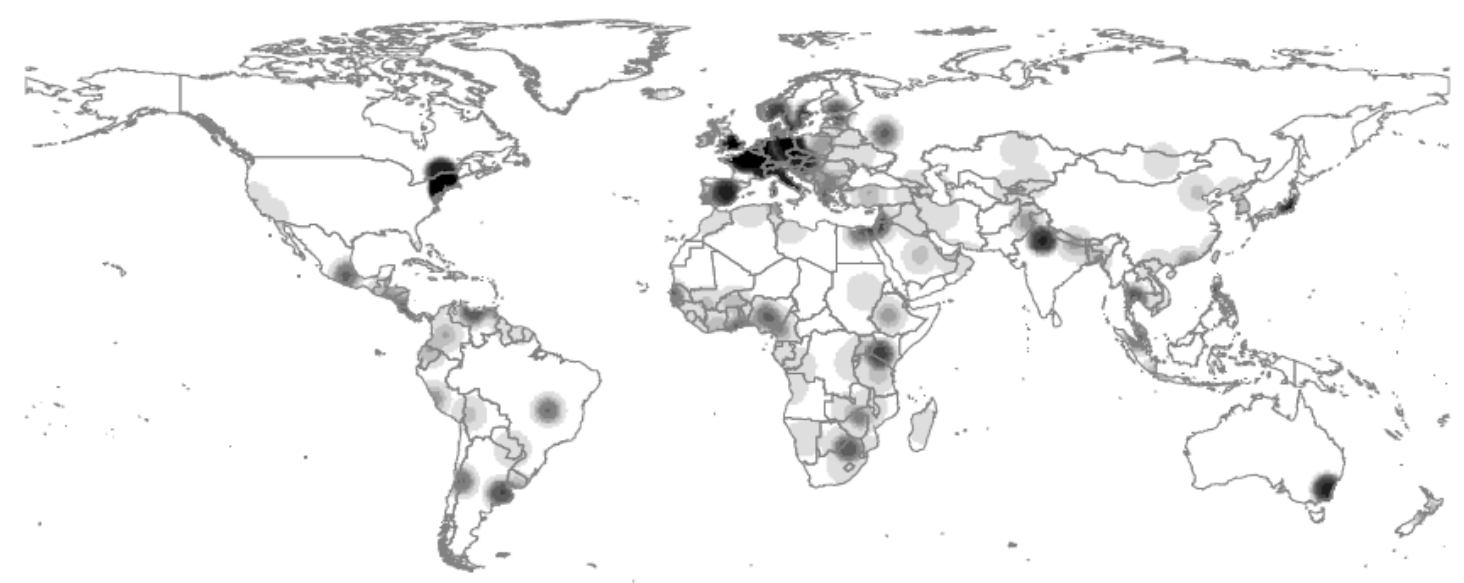

Figura 1. Mapa da densidade das ligações (ligações que entram e ligações que saem)

\section{Densidade da rede}

A densidade total da rede de ONGIs é extremamente baixa:0.03\%. Por outras palavras, em 10,000 ligações possíveis só se realizaram três ligações. Este resultado é muito informativo se comparado com a densidade das outras redes globais. A comparação da densidade entre as três redes diferentes- de países ligados por ONGIs, por embaixadas e por comércio - revela que as redes interestados e do comércio global são muito mais densas do que a rede da sociedade civil global (ver Quadro 2). A rede de comércio global é quase 6 vezes mais densa, e a densidade da rede inter-estados é o dobro da da rede de ONGIs.

\begin{tabular}{|c|c|c|c|c|}
\hline \multicolumn{3}{|c|}{ Comércio - ONGIs } & \multicolumn{2}{|l|}{ Embaixadas-ONGIs } \\
\hline $\begin{array}{l}\text { Densidade- } \\
\text { comerciais }\end{array}$ & Ligações & 0.402 & $\begin{array}{l}\text { Densidade - ligações } \\
\text { consulares }\end{array}$ & 0.147 \\
\hline $\begin{array}{l}\text { Densidade - } \\
\text { entre ONGIs }\end{array}$ & ligações & 0.072 & $\begin{array}{l}\text { Densidade- } \\
\text { entre ONGIs }\end{array}$ & 0.072 \\
\hline Diferença & & 0.331 & Diferença & 0.076 \\
\hline $\begin{array}{l}\text { Bootstrap t-sta } \\
(5,000 \text { perm }\end{array}$ & $\begin{array}{l}\text { țtic } \\
\text { ções) }\end{array}$ & 13.535 & $\begin{array}{l}\text { Bootstrap t-statistic } \\
(5,000 \text { permutações })\end{array}$ & 4.711 \\
\hline Significancia & & 0.0002 & Significancia & 0.0002 \\
\hline
\end{tabular}

Quadro 2. Comparação das densidades

\section{I gualdade: Estrutura centro-periferia}

A análise de clusters realizada nos resultados de coreness da rede revelam uma estrutura claramente centro/semi-periferia/periferia nas três redes de países mencionadas em cima (ver Figura 2). O gráfico mostra os resultados de coreness dos países que se aglomeram claramente em três grupos, designados por baixa, média, e alta proximidade ao centro da rede. No entanto, as diferenças entre centro, semi-periferia, e periferia são consideravelmente mais pronunciadas na rede de países por ONGIs, quando comparadas com as outras duas redes ( como se pode ver na maior variância nos resultados de coreness entre centro, semiperiferia e periferia na rede de países por ONGIs). Outro aspecto a mencionar é que o centro é consideravelmente mais pequeno na rede de países por ONGIs (inclui 18 países enquanto que nas outras redes inclui 51 e 87). 

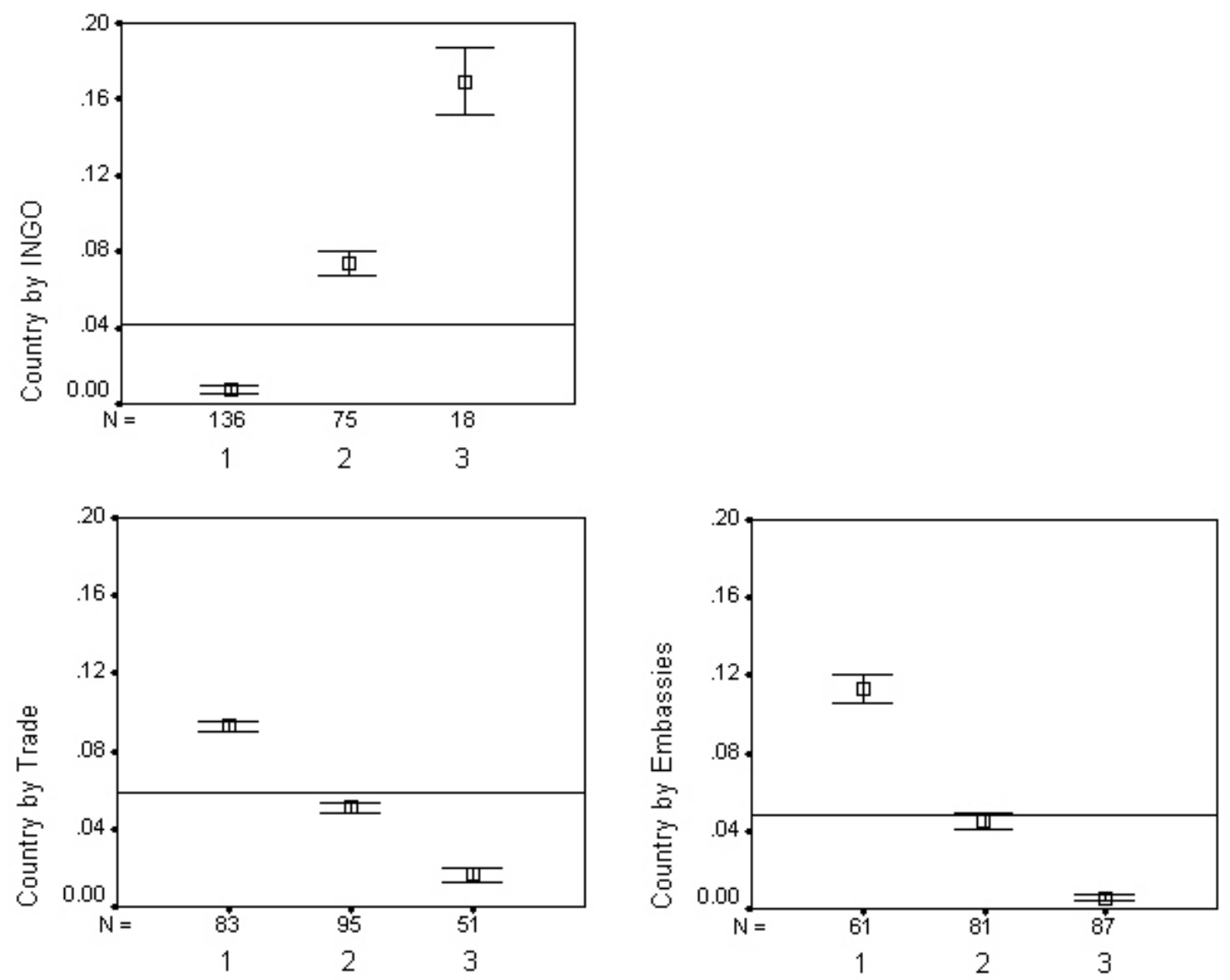

Figura 2. Estrutura centro-periferia dos países por ONGIs, comércio e embaixadas

Quem constitui o centro ? Os países desenvolvidos tendem a estar sobre representadas no centro das três redes "por países" , mas este efeito é mais forte na rede de países por ONGIs. PO exemplo, é quase oito vezes mais provável que os países da Europa Ocidental estejam incluídos no centro da rede de países por ONGIs, do que a percentagem que representam no total dos países nos levaria a esperar. Em comparação, estão muito menos sobre representados na rede de comércio, um pouco mais do que o dobro do que a sua percentagem no total dos países, e quase três vezes mais do que seria de esperar na rede de embaixadas. Logo, não só a rede de ONGIs é a mais polarizada, o seu centro também está mais enviesado para o Norte do que o das redes inter-paises e comerciais .

\section{I ntegração da rede}

A análise de componentes mostra que a rede é quase totalmente contígua - é composta por um único grande componente, que inclui $97.4 \%$ de todas as ONGIs da base de dados $(9,738$ organizações). Quase todos os restantes nodos estavam isolados ( ou seja, tinham zero ligações). No entanto, um grande componente pode consistir em sub grupos que estão interligados de forma folgada. A análise de correspondência (ilustrada na figura 3 e Quadro 3) mostra que este não é o caso. Os resultados são compatíveis com os da análise de componentes: a análise produziu um cluster muito grande (designado a) que inclui mais de 9/10 da rede total em termos de nodos e ligações, mostrando que, a fragmentação global da rede é baixa. 


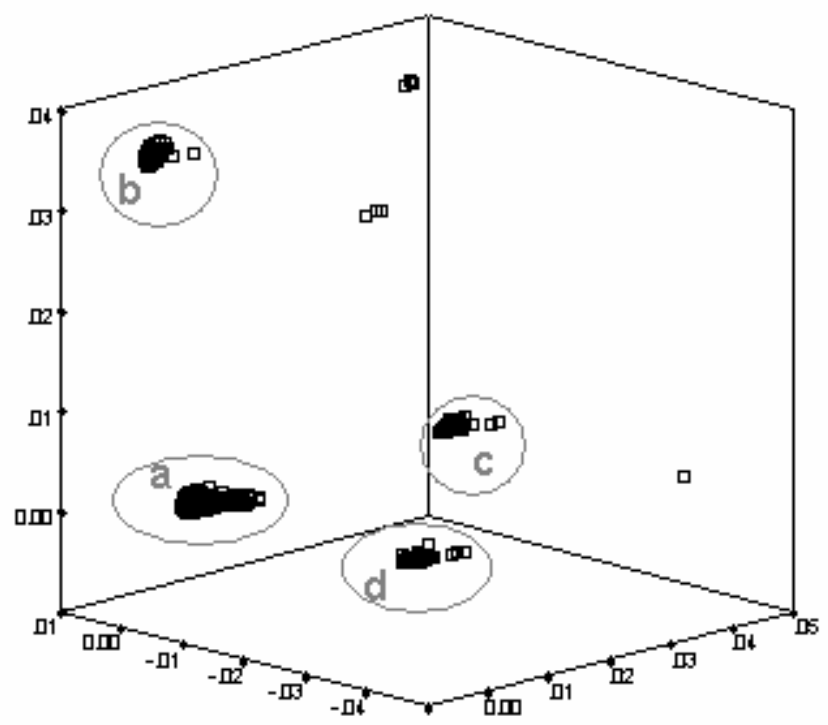

Figura 3. Scatter plot dos resultados da análise de correspondência

\begin{tabular}{llll}
\hline & $\begin{array}{l}\text { Organizações } \\
(\%)\end{array}$ & $\begin{array}{l}\text { Ligações } \\
\text { enviadas } \\
(\%)\end{array}$ & $\begin{array}{l}\text { Ligações } \\
\text { recebidas } \\
(\%)\end{array}$ \\
\hline a & $93.20 \%$ & $93.60 \%$ & $91.14 \%$ \\
b & $2.02 \%$ & $1.86 \%$ & $2.60 \%$ \\
c & $1.37 \%$ & $1.23 \%$ & $1.74 \%$ \\
d & $1.36 \%$ & $1.01 \%$ & $1.81 \%$ \\
\hline
\end{tabular}

Quadro 3. Organizações e ligações nos grupos coesos

Deve mencionar-se também, nenhum dos clusters é específico a um tema ou região, e que todos os clusters incluem uma variedade de organizações. Assim, a rede é coesa, e ao mesmo tempo diversa e inclusiva.

Mas quem está ligado com quem nestes clusters heterogéneos? Será que as ligações atravessam grupos de organizações ou têm lugar maioritariamente dentro dos grupos? A análise das ligações internas vs externas ao grupo revelam dados interessantes (ver Quadro 4). O índice E-I para as regiões é positivo e estatisticamente significante, reflectindo uma tendência de ligações através de regiões, enquanto que o E-I negativo para níveis de rendimento revela uma tendência para a criação de ligações intra-estrato (ambos os índices são estatisticamente significantes, e dado que este é um índice E-I modificado, que tem em atenção o impacto da composição do grupo, a importância deste resultado não se explica só pelo facto de $80 \%$ das organizações pertencerem a países com rendimentos elevados; e o resultado negativo é realmente demonstrativo ). A conclusão é que enquanto que as ONGIs tendem a ligar-se através de linhas regionais, elas tendem a conectar-se entre países com níveis semelhantes de rendimentos (na verdade, a maior parte das ligações são entre países com altos níveis de rendimento, na maioria entre a Europa e os EUA . 


\begin{tabular}{lllll}
\hline & Interna & Externa & E-I & $\begin{array}{l}\text { Significância } \\
(5,000 \\
\text { permutações })\end{array}$ \\
\hline $\begin{array}{l}\text { Região } \\
\text { Rendime }\end{array}$ & $33.3 \%$ & $66.7 \%$ & 0.334 & 0.035 \\
nto & $32.6 \%$ & -0.347 & 0.034 \\
País & $7.4 \%$ & $92.6 \%$ & 0.852 & 0.353 \\
\hline
\end{tabular}

Quadro 4. Ligações intra - grupo e inter- grupo - índice E-I global

De assinalar também, que organizações da mesma área (e.g., apoio/asistência, Comércio ) não tendem a criar sub-redes exclusivas específicas ao tema. A análise mostra que as ligações são mais frequentemente entre organizações que estão empenhadas em áreas de actuação diferentes (usando a Classificação Internacional das Organizações não lucrativas [ICNPO]: Salamon \& Anheier, 1992). Mais de $2 / 3(70 \%)$ das ligações na matriz são entre classes de ICNPO diferentes, e o índice E-I, 0.39, aponta uma tendência das ligações para fora do grupo.

Por esta razão , a rede apresenta uma integração substancial, qual seja a forma de olhar para ela. Todas as análises levadas a cabo indiciam que a rede global de ONGIs é muito coesa, e possui ligações fortes entre grupos inter-regionais, temáticos, e de outros tipos.

\section{Ligações com I GOs}

A análise de como as IGOs estão ligadas com as ONGIs não apresenta um padrão significante. As ONGIs que são mais centrais na rede não têm ligações mais predominantes com as IGOs, e as ONGIs que têm ligações com as IGOs não têm forçosamente mais ligações com outras ONGIS que têm ligações com IGOs. O padrão das ligações das IGOs na rede das ONGIs parece aleatório, e não indicia um empenhamento estratégico das IGOs na rede de ONGIs.

\section{Discussão}

Este estudo apresenta uma primeiríssima análise das redes da sociedade civil global numa escala verdadeiramente global, e um dos primeiros testes empíricos explicitamente direccionado para o argumento dual neo-Gramsciano, respeitante ao papel da sociedade civil global no jogo hegemónico global.

Os resultados são ambivalentes, pois apoiam ambos os lados da visão dialéctica Gramsciana da sociedade civil. Deste modo, poderíamos argumentar que a sociedade civil global está a passar por um lento processo de formação contrahegemónica. Isto explica porque é que a rede está tão bem integrada mas ainda pouco desenvolvida, assim como porque é que as disparidades e hierarquia estão ainda presentes. Só com o tempo se poderá dizer que direç̧ão tomará no futuro. A actual estrutura bem integrada da rede da sociedade civil actual, a partir da qual poderá emergir um bloco histórico contra-hegemónico, é um sinal positivo para os que defendem um tal desenvolvimento. Pode fornecer uma infraestrutura global compreensiva para uma futuro movimento global compreensivo, na condição de que outros factores tais como consciencialização, ideologia e agência se seguirão.

Claramente, o processo pode ir na direcção oposta. É possível que forças hegemónicas estejam a minar o potencial da sociedade civil global se desenvolver nesta direcção, e que o desenvolvimento insatisfatório da rede da sociedade civil global seja o resultado da actuação da agência hegemónica. Enquanto que as ligações IGO incluídas na rede de ONGIs não apresentam nenhum padrão que apoie este argumento, é certamente razoável afirmar que algumas das características da rede global de ONGIs resultam de constrangimentos estruturais da economia politica global, levada a cabo por governos, IGOs, acordos 
comerciais, e outros elementos da ordem hegemónica mundial. Será necessário repetir esta análise dentro daqui a 10 anos para perceber se prevaleceram as forças hegemónicas ou contra-hegemónicas.

Para além disto, para compreender porque é que os resultados são inconclusivos devemos regressar a Gramsci. A visão de Gramsci's da sociedade civil e hegemonia é primeiro e antes de mais uma visão dialéctica. Para Gramsci, a sociedade civil é tudo ao mesmo tempo hegemónica e contra-hegemónica. Ronaldo Munck alerta para a ambiguidade no modelo de Gramsci: " uma releitura de Gramsci numa base contextual e histórica mostraria que ele concebia a sociedade civil simultaneamente como sendo a arena em que a hegemonia capitalista era exercida e o terreno no qual as classes subalternas da sociedade moderna podiam forjar alianças e contestar tal hegemonia" (Munck, 2004, pp. 19-20).

A hegemonia e a contra-hegemonia devem ser vistas como "movimentos duplos simultâneos" que se influenciam reciprocamente (Persaud, 2001), e uma mudança de hegemonia é seguida pelo nascimento de novas forças contrahegemónicas entre as elites recentemente retiradas. Estudiosos da sociedade civil ignoram frequentemente a sua natureza dialéctica, e preferem olhar só para "o lado favorável " . Os resultados deste texto apoiam esta releitura de Gramsci, e podem servir como uma chamada de atenção para aqueles que tentam encontrar uma contra-hegemonia ou hegemonia perfeitas no mundo real das relações de poder globais com a sociedade civil global.

\section{E a seguir? ? I mplicações estratégicas para a sociedade civil global}

Consoante o argumento de Gramsci, todos os grupos subjugados devem participar no bloco histórico. A reduzida fragmentação encontrada na gigantesca rede de ONGIs é uma pré-condição para a emergência de um bloco global. A sua estrutura integrada constitui uma infra-estrutura adequada para um bloco histórico bem integrado, pois não permite que a elite hegemónica o divida e conquiste. A sua interacção constitui a fundação a partir da qual um movimento global unificado pode emergir, uma vez que outras condições (nomeadamente a adopção de uma ideologia reformista e uma orientação para a acção)estejam preenchidas.

No entanto, nem todas as condições necessárias à formação de um bloco histórico foram preenchidas. A rede global de ONGI's é desproporcionalmente constituída por organizações de países ricos, sendo raras as organizações do Sul. Por exemplo, muito poucas organizações africanas estão ligadas a esta rede. Da mesma forma, a rede é substancialmente subdesenvolvida - tem uma densidade muito baixa, muito mais baixa que a das redes hegemónicas globais. O carácter esparso e a limitada inclusão da rede global de ONGIs enfraquece a capacidade de formação de uma contra-força viável ao sistema de governação global. A estrutura da rede não é equitativa ; reproduz as disparidades de poder que existem no sistema - mundial capitalista. Esta estrutura desigual e centralizada pouco provavelmente fomentará a solidariedade necessária ao desenvolvimento de um bloco histórico contra-hegemónico.

Que tipos de acções deveriam adoptar os apoiantes de um contra movimento global? Existem vários passos estratégicos que podem ser dados para promover tais desenvolvimentos. AS perspectivas de um movimento global aumentarão se o número de ONGIs do Sul aumentarem a um ritmo mais rápido que as do Norte, e se a rede mantiver o presente nível de integração. Para aumentar a inclusão e a participação, e obter um aumento da representatividade e legitimidade, os activistas devem ampliar estrategicamente as ligações entre as ONGs do Norte e do Sul. Para isto, as ONGIs têm que construir activamente coligações com os activistas do Sul. Uma das formas através das quais as ONGIs o podem conseguir é abrindo as suas conferências ou encontros anuais a um grupo mais vasto de 
partes interessadas para além dos seus membros e funcionários. Outra forma é transformar o encontro anual das ONGIs numa conferência internacional para debater tópicos de interesse para a organização, criando um local onde a organização pode identificar colaboradores potenciais (Koenig, 2004). Ainda uma outra forma de expansão das redes das ONGIs do Norte é criando uma comité internacional de aconselhamento, ou convidando pessoas chave de países em desenvolvimento para fazerem parte da direcção da organização. Esta é uma forma de criar pontes entre as ONGIs e as ONGs locais e fazer ligações à sociedade civil local, uma estratégia que a American Society for Association Executives considerou ser uma das melhores prática em termos de planeamento estratégico (ASAE, 2005).

Da parte das ONGIs do Sul, o que é necessário é aumentar capacidades. Muitas das ONGIs do Sul tem falta de recursos, de oportunidade, ou de know-how organizativo para se tornarem mais globais. Uma solução possível pode ser a criação de oportunidades de interacção para as organizações, como as que constituem os fóruns sociais, em especial o Fórum Mundial Social e os fóruns sociais temáticos. Estes eventos deveriam considerar a atribuição de mais recursos do seu orçamento para a promoção de países e regiões que estão menos representadas. I gualmente, as grandes ONGIs, as agências da ONU, e outros actores globais deveriam apoiar as ONGs do Sul a obter o know-how politico e organizativo necessário à participação de sucesso nas redes globais. Facilitar o acesso à Internet e fornecer formação em comunicações, por exemplo, pode ser uma ajuda para aumentar o acesso à informação de outras organizações que trabalham em temas semelhantes.

Mais importante que tudo, o número de ONGIs do Sul tem que aumentar. Uma forma e conseguir isto é ajudando as ONGs locais a participarem em redes regionais ou globais; outra é estabelecendo nos países em desenvolvimento, sedes locais de ONGIs do Norte e cooperar com outras organizações locais. Outros actores importantes nesta área são os grandes doadores e as fundações. Este podem ajudar financiando algumas das estratégias listadas acima, ou adoptando políticas que incentivem a construção de coligações. Por exemplo, dando prioridade às colaborações Norte-Sul, diminuindo as exigências de investimento equiparado ou obrigando esse tipo de coligações nos pedidos de submissão de propostas. Mas primeira coisa que tem que acontecer é o reconhecimento do potencial das redes, e do que falta fazer para atingir esse potencial. Por esta razão, o activismo mais necessário vem da investigação que ajuda a melhorar o conhecimento da sociedade civil global. Deveriam ser criadas mais bases de dados da sociedade civil global e dos actores que operam dentro dela, e aquelas que já existem deveriam esta mais disponíveis para a investigação. O papel dos investigadores - activistas é levar a cabo investigação que considere a sociedade civil como um projecto político global, e estudá-lo numa perspectiva verdadeiramente global.

\section{Agradecimentos}

Agradeço a Helmut Anheier, Phillip Bonacich, Leo Estrada, Zeke Hasenfeld e Stuart Kirk, pela orientação nesta investigação, e a Jan De Leew pela ajuda na execução da análise de correspondência.

\section{Referências}

Amoore, L., Dodgson, R., Gills, B. K., Langley, P., Marshall, D., and Watson, I. (2000). "Overturning 'globalization': Resisting teleology, reclaiming Politics". In: B. K. Gills (ed.), Globalization and the Politics of Resistance, London: Macmillan, pp. 12-28. 
Anheier, H. K., e Katz, H. (2003). "Mapping global civil society". In: M. Kaldor, H. Anheier, and M. Glasius (eds.), Global Civil Society 2003, Oxford: Oxford University Press, pp. 241-258.

ASAE (2005). "The international journey: Different paths to take". American Society for Association Executives.

Batliwala, S. (2002). "Grassroots movements as transnational actors: Implications for global civil society". Voluntas 13, 393-409.

Bigman, D. (2002). "The pros and cons of globalization for developing countries". In: D. Bigman (ed.), Globalization and the Developing Countries: Emerging Strategies for Rural Development and Poverty Alleviation, The Hague: CABI Publishing in association with ISNAR, pp. 27-79.

Bocock, R. (1986). Hegemony. London: Tavistock Publications.

Boli, J., e Thomas, G. M. (1997). "World culture in the world polity: A century of international non-governmental organization". Annual Sociological Review 62, 171- 190.

Borgatti, S. P., e Everett, M. G. (1999). "Models of core-periphery structures". Social Networks 21, 375-395.

Borgatti, S. P., Everett, M. G., e Freeman, L. C. (2002). Ucinet for Windows: Software for social network analysis. Harvard, MA: Analytic Technologies

Carroll, W. K. (1992). "Social movements and counter-hegemony: Canadian contexts and social theories". In: W. K. Carroll (ed.), Organizing Dissent: Contemporary Social Movements in Theory and Practice: Studies in the Politics of Counter-Hegemony, Toronto: Garamond Press, pp. 3-38.

Carroll, W. K., e Carson, C. (2003). "The network of global corporations and elite policy groups: A structure for transnational capitalist class formation?". Global Networks 3, 29-57.

Castells, M. (1989). The Informational City: Information Technology, Economic Restructuring, and the Urban-Regional Process. Oxford: Blackwell.

Castells, M. (1997). The Power of Identity. Malden, MA: Blackwell.

Cock, J. (2004). "The World Social Forum and new forms of social activism". In: R. Taylor (ed.), Creating a Better World: Interpreting Global Civil Society, Bloomfield, CT: Kumarian Press, pp. 170-183.

Cox, R. W. (1993). "Gramsci, hegemony and International Relations". In: S. Gill (ed.), Gramsci, Historical Materialism and International Relations, Cambridge: Cambridge University Press, pp. 49-66.

Cox, R. W. (1996). Approaches to World Order. Cambridge: Cambridge University Press.

Cox, R. W. (2002). The Political Economy of a Plural World: Globalization and Civilization. New York: Routledge.

Diani, M. (2003). "Leaders or brokers: Positions and influence in social movement networks". In: M. Diani and D. McAdam (eds.), Social Movements and Networks: 
Relational Approaches to Collective Action, Oxford: Oxford University Press, pp. 105- 122.

Dicken, P. (1998). Global Shift: Transforming the World Economy. New York: Guilford Press.

Edwards, M. (1999). “International development NGOS: Agents of foreign aid or vehicles for international cooperation?". Nonprofit and Voluntary Sector Quarterly 28, 25-37.

Esping-Andersen, G. (1996). "After the Golden Age? Welfare state dilemmas in a global economy". In: G. Esping-Andersen (ed.), Welfare States in Transition: National Adaptation in Global Economies, London: Sage, pp. 1-31.

ESRI [Environmental Research Systems Institute] (2005). ArcGIS Desktop. Redlands, CA: Environmental Research Systems Institute.

Falk, R. (2000). “Resisting 'globalization from above' through 'globalization from below' In: B. K. Gills (ed.), Globalization and the Politics of Resistance, London: Macmillan, pp. 46-56.

Falk, R. (2003). "On the political relevance of global civil society". In: J. H. Dunning (ed.), Making Globalization Good: the Moral Challenges of Global Capitalism, Oxford: Oxford University Press, pp. 280-300.

Florini, A., and Simmons, P. J. (2000). "What the world needs now?" In: A. Florini (ed.), The Third Force: The Rise of Transnational Civil Society, Tokyo, Washington DC: Japan Center for International Exchange, Washington Carnegie Endowment for International Peace, pp. 1-16.

Forgacs, D. (1988). An Antonio Gramsci Reader: Selected Writings, 1916-1935. New York: Schocken Books.

Gills, B. K. (2000). "Introduction: Globalization and the politics of resistance". In: B. K. Gills (ed.), Globalization and the Politics of Resistance, London: Macmillan, pp. 3-11.

Gramsci, A. (1971). Selections from the Prison Notebooks of Antonio Gramsci. London: Lawrence \& Wishart.

Kaldor, M. (2001). "A decade of humanitarian intervention: The role of global civil society". In: H. Anheier, M. Glasius, and M. Kaldor (eds.), Global Civil Society 2001, Oxford: Oxford University Press, pp. 109-143.

Kaldor. M, Anheier, H., e Glasius, M. (2003). "Global civil society in an era of regressive globalization". In: M. Kaldor, H. Anheier, and M. Glasius (eds.), Global Civil Society 2003, Oxford: Oxford University Press, pp. 3-33.

Katz, H., e Anheier, H. (2005). "Global connectedness: The structure of transnational NGO networks". In: H. Anheier, M. Kaldor, e M. Glasius (eds.) Global Civil Society, 2005/6, London: Sage,

Keck, M., e Sikkink, K. (1998). Activists Beyond Borders: Trasnational Activists in International Politics. Ithaca, NY: Cornell University Press.

Khagram, S. (2002). "Restructuring the global politics of development: The case of India's Narmada valley dams". In: S. Khagram, J. V. Riker, e K. Sikkink (eds.), 
Restructuring World Politics: Transnational Social Movements, Networks, and Norms, Minneapolis: University of Minnesota Press, pp. 206-230.

Koenig, B. L. (2004). Going Global for the Greater Good: Succeeding as a Nonprofit in the Global Community. San Francisco: Jossey-Bass.

Maher, J. (ed.) (2001). Europa World Year Book 2001, Vols. I \& II: Europa Publications.

McGrath, C., e Krackhardt, D. (2003). "Network conditions for organizational change". The Journal of Applied Behavioral Science 39, 324-336.

Moen, D. G. (1998). "Analysis of social transformative movements in advanced capitalism: A neo-Gramscian approach". J ournal of Policy and Culture 3, 117-133.

Munck, R. (2004). "Global civil society: Myths and prospects". In: R. Taylor (ed.), Creating a Better World: Interpreting Global Civil Society, Bloomfeld, CT: Kumarian Press, pp. 13-26.

Persaud, R. B. (2001). Counter-Hegemony and Foreign Policy: The Dialectics of Marginalized and Global Forces in Jamaica. New York: State University of New York Press.

Pollin, R. (2000). Globalization, I nequality and Financial Instability: Confronting the Marx, Keynes and Polanyi Problems in the Advanced Capitalist Economies. Working Paper No. 8, University of Massachusetts, Political Economy Research Institute, Amherst, MA.

Ramia, G. (2000). "Global social policy, INGOs and strategic management: An emerging research agenda". Global Social Policy 3, 79-101.

Ratner, R. S. (1992). "New movements, new theory, new possibilities? Reflections on counter-hegemony today". In: W. K. Carroll (ed.), Organizing Dissent: Contemporary Social Movements in Theory and Practice: Studies in the Politics of Counter-Hegemony, Toronto: Garamond Press, pp. 234-242.

Rupert, M. (1993). "Alienation, capitalism and the inter-state system". In: S. Gill (ed.), Gramsci, Historical Materialism and International Relations, Cambridge: Cambridge University Press, pp. 67-92.

Salamon, L. M., e Anheier, H. K. (1992)."In search of the nonprofit sector II: The problem of classification". Voluntas 3, 267-309.

Salm, J. (1999). "Coping with globalization: A profile of the northern NGO sector". Nonprofit and Voluntary Sector Quarterly 28, 87-103.

Sassoon, A. S. (1982). "Hegemony, war of position, and political intervention". In: A. S. Sassoon (ed.), Approaches to Gramsci, London: Writers and Readers, pp. 94- 115 .

Snijders, T. A. B., e Borgatti, S. P. (1999). "Non-parametric standard errors and tests for network statistics". Connections 22, 61-70.

Taylor, P. J., Watts, M., e Johnston, R. J. (2002). "Geography/Globalization". In: R. J. Johnston, P. J. Taylor, e M. Watts (eds.), Geographies of Global Change: Remapping the World, Malden, MA: Blackwell, pp. 1-18. 
Taylor, R. (ed.) (2004). Creating a Better World: Interpreting Global Civil Society, Bloomfield, CT: Kumarian Press.

Tickell, A., and Peck, J. A. (2003). "Making global rules: Globalization or neoliberalization?" In: J. A. Peck and H-W. C. Yeung (eds.), Remaking the Global Economy: Economic-Geographical Perspectives, London: Sage, pp. 163-181.

Tvedt, T. (2004). "Development NGOs: Actors in a global civil society or in a new international social system?" In: R. Taylor (ed.), Creating a Better World: Interpreting Global Civil Society, Bloomfeld, CT: Kumarian Press, pp. 133-146.

Ulvila, M., and Hossain, F. (2002). "Development NGOs and political participation of the poor in Bangladesh and Nepal". Voluntas 13, 149-163.

WSF [World Social Forum] (2004). Programme: WSF organised. Mumbai: World Social Forum. 